\title{
THE EFFECT OF TRIFLURALIN ON POST-IN VITRO MORPHOGENESIS OF FIVE GENOTYPES OF HEAD CABBAGE (BRASSICA OLERACEAE VAR. CAPITATA)
}

\author{
Short communication \\ Oushadee A.J. ABEYAWARDANA*1,3, Iva VIEHMANNOVÁ ${ }^{2}$, Martin KOUDELA $^{1}$ \\ ${ }^{1}$ Department of Horticulture, Faculty of Agrobiology, Food and Natural Resources \\ Czech University of Life Sciences Prague, Kamýcká 129, 16500 Prague-Suchdol, Czech Republic \\ ${ }^{2}$ Department of Crop Sciences and Agroforestry, Faculty of Tropical AgriSciences \\ Czech University of Life Sciences Prague, Kamýcká 129, 16500 Prague-Suchdol, Czech Republic \\ ${ }^{3}$ Laboratory of Plant reproduction, Institute of Experimental Botany \\ Czech Academy of Sciences, Národní 3, 11720 Prague 1, Czech Republic
}

Received: November 2020; Accepted: March 2021

\begin{abstract}
Six genotypes of head cabbage ('Flexima', 'Mutsuma', 'Septima', 'Zeus', DC6, 'Ancoma') have been studied to find an effective method of obtaining polyploids using trifluralin. The effect of various trifluralin concentrations $\left(0.5,1.0,1.5\right.$, and $\left.2.0 \mathrm{mg} \cdot \mathrm{L}^{-1}\right)$ and treatment conditions $\left(24{ }^{\circ} \mathrm{C} / 24 \mathrm{~h}, 24{ }^{\circ} \mathrm{C} / 48 \mathrm{~h}, 30{ }^{\circ} \mathrm{C} / 24 \mathrm{~h}\right.$, and $30{ }^{\circ} \mathrm{C} / 48 \mathrm{~h}$ ) on organogenesis of organogenic callus, hypocotyl, and seeds was tested. Ploidy level was detected using a flow cytometer. As a result, low survival of hypocotyls and calli was obtained. The shoots induced from calli and hypocotyls failed to develop quality plantlets and most calli and hypocotyls remained recalcitrant for further differentiation. Treated seeds seemed to be promising objects basing on a considerable percentage of plant regeneration. With the increased concentration of trifluralin and increasing press of treatment conditions, the seed germination rate was significantly reduced. Shoot induction from germinated seeds varied among genotypes and treatments. The root induction was independent of treatments but also reduced considerably compared to the control. Under tested conditions, none of the polyploids resulted. Further studies are required to be successful in protocol development.
\end{abstract}

Key words: cabbage, explants, in vitro culture, regeneration, trifluralin, polyploids

\section{INTRODUCTION}

Polyploidization is a tool used either under in vivo and in vitro conditions in crop breeding programs to obtain a good source of material for further selection and/or hybridization. Mitotic and meiotic polyploidization, are the two different ways employed in artificial polyploids induction.

Generally, mitotic polyploidization is based on the application of antimitotic agents. Colchicine, the widely using chromosome doubling agent, amiprophos-methyl (APM), butamifos, oryzalin, propyzamide, trifluralin have been successfully tested for different species (Hansen \& Andersen 1996, 1998;
Petersen et al. 2003; Cheng et al. 2012; Orcen \& Emiroglu 2014). Nowadays, the substitution of antimitotic agents with compounds of lower toxicity to humans than colchicine, is widely testing across different crops. It has been reported that trifluralin, the component of herbicides, is more specific for plant tubulin and mitosis in vitro with less phytotoxicity and efficient chromosome doubling (Khosravi et al. 2008).

Cabbage (B. oleracea var. capitata) is a wellknown diploid vegetable containing high amounts of antioxidants such as glucosinolates. There are many reported studies of using trifluralin in vitro chromosome doubling in cabbage following microspore 
culture (Rudolf et al. 1999; Yuan et al. 2015) for double haploid induction. Autopolyploid induction in somatic tissues can raise new beneficial traits such as biotic or abiotic resistance, higher yield, higher glucosinolate content, and so on, due to either increased gene expression as a result of double sets of chromosomes or by gene redundancy promoting a buffering effect of deleterious recessive alleles and maintain the high level of heterozygosity (reviewed by Sattler et al. 2016). But lack of standardized precise methodology for in vitro polyploidization and clonal propagation limits the application of this technique in in vitro chromosome doubling in diploid tissues. The success of the technique relies on several variables, such as crop species, cultivar, explant, type of antimitotic agent and its concentration, treatment duration, application method, and so on. It is worth studying the influence of trifluralin, on the postin vitro culture development of head cabbage and its effect on ploidy induction. As a starting step towards developing a successful in vitro protocol for polyploid induction using trifluralin as an antimitotic agent, in this study, we focused on examining the post effect of trifluralin on in vitro culture development of head cabbage starting from different explants following different trifluralin treatments. This study can provide a background for further studies on establishing reliable in vitro culture protocol and selecting appropriate explant for polyploid induction using trifluralin for head cabbage.

\section{MATERIALS AND METHODS}

\section{Plant materials}

Seeds of six genotypes of white head cabbage, cultivars 'Flexima' (F), 'Mutsuma' (M), 'Septima' (S), 'Zeus' (Zeu), 'Ancoma' (Anco), and breeding line DC6 obtained from MoravoSeed CZ a.s. (Czech Republic) and Reprosam s.r.o. (Czech Republic) were used in this study. Three different explants, seeds, hypocotyl, and organogenic calli were used. Hypocotyl segments were excised from 6-day old in vitro derived seedlings on MS (Murashige \& Skoog 1962) seed germination medium supplemented with sucrose $\left(10 \mathrm{~g} \cdot \mathrm{L}^{-1}\right)$, phytagel $\left(7 \mathrm{~g} \cdot \mathrm{L}^{-1}\right)$ at $\mathrm{pH}$ 5.8. The cultures were incubated in a 16 hour light at $25^{\circ} \mathrm{C} \pm 2{ }^{\circ} \mathrm{C}$. Organogenic calli were derived from 6-day old hypocotyl fragments on MS callus induction medium supplemented with nicotinic acid $\left(1 \mathrm{mg} \cdot \mathrm{L}^{-1}\right)$, thiamine- $\mathrm{HCl}\left(10 \mathrm{mg} \cdot \mathrm{L}^{-1}\right)$, pyridoxine- $\mathrm{HCl}\left(1 \mathrm{mg} \cdot \mathrm{L}^{-1}\right)$, myo-inositol $\left(100 \mathrm{mg} \cdot \mathrm{L}^{-1}\right)$, NAA $\left(0.2 \mathrm{mg} \cdot \mathrm{L}^{-1}\right)$, BAP $\left(3 \mathrm{mg} \cdot \mathrm{L}^{-1}\right), \mathrm{AgNO}_{3}$ $\left(0.5 \mathrm{mg} \cdot \mathrm{L}^{-1}\right)$, sucrose $\left(20 \mathrm{~g} \cdot \mathrm{L}^{-1}\right)$, and phytagel $\left(7 \mathrm{~g} \cdot \mathrm{L}^{-1}\right)$ at $\mathrm{pH} 5.8$ at $25^{\circ} \mathrm{C} \pm 2{ }^{\circ} \mathrm{C}$ in 16 hour light.

\section{Trifluralin treatment and in vitro culture}

Explants were subjected to various trifluralin concentrations $\left(0.5,1.0,1.5\right.$, and $\left.2.0 \mathrm{mg} \cdot \mathrm{L}^{-1}\right)$ and treatment conditions $\left(24{ }^{\circ} \mathrm{C} / 24 \mathrm{~h}, 24{ }^{\circ} \mathrm{C} / 48 \mathrm{~h}, 30^{\circ} \mathrm{C} / 24 \mathrm{~h}\right.$, and $30{ }^{\circ} \mathrm{C} / 48 \mathrm{~h}$ in dark). Hypocotyl and calli explants were incubated in liquid MS medium supplemented with vitamins as above, sucrose $\left(20 \mathrm{~g} \cdot \mathrm{L}^{-1}\right)$, and trifluralin (each concentration separately) at $\mathrm{pH}$ 5.8. Seeds were subjected to the same trifluralin treatments in half-strength MS medium. The control treatment was conducted using the same liquid MS medium without trifluralin. Two replicate trials were conducted for each treatment. Each trial involved four Petri plates with six calli, ten hypocotyls, and seven seeds. After the successive treatment, explants calli, seeds, and hypocotyls were washed three times and cultured on MS callus induction medium, MS seed germination medium mentioned above and MS shoot induction medium supplemented with vitamins as above, plus $\mathrm{NAA}\left(0.2 \mathrm{mg} \cdot \mathrm{L}^{-1}\right), \mathrm{BAP}\left(3 \mathrm{mg} \cdot \mathrm{L}^{-1}\right), \mathrm{GA}_{3}\left(0.01 \mathrm{mg} \cdot \mathrm{L}^{-1}\right)$, $\mathrm{AgNO}_{3}\left(0.5 \mathrm{mg} \cdot \mathrm{L}^{-1}\right)$, sucrose $\left(20 \mathrm{~g} \cdot \mathrm{L}^{-1}\right)$, and phytagel $\left(7 \mathrm{~g} \cdot \mathrm{L}^{-1}\right)$ at $\mathrm{pH}$ 5.8. After one week, calli were transferred to fresh same MS shoot induction medium. In every two weeks, shoots produced on calli and hypocotyls were repeatedly transferred to a fresh medium of the same composition and incubated at the culture conditions described above until developing typical and possible to dissect from mother explant small shoots (1-2 cm height).

Shoot tips of seven days old seedlings derived from treated seeds were excised and cultured on MS shoot development medium supplemented with vitamins, NAA $\left(0.2 \mathrm{mg} \cdot \mathrm{L}^{-1}\right)$, BAP $\left(3 \mathrm{mg} \cdot \mathrm{L}^{-1}\right)$, $\mathrm{GA}_{3}\left(0.01 \mathrm{mg} \cdot \mathrm{L}^{-1}\right)$, sucrose $\left(20 \mathrm{~g} \cdot \mathrm{L}^{-1}\right)$, and phytagel $\left(7 \mathrm{~g} \cdot \mathrm{L}^{-1}\right)$ at $\mathrm{pH}$ 5.8. Cultures were incubated for several weeks with repeated transferring into fresh media till they reached $2-3 \mathrm{~cm}$ height. MS rooting medium supplemented with IBA $\left(0.2 \mathrm{mg} \cdot \mathrm{L}^{-1}\right)$, sucrose $\left(10 \mathrm{~g} \cdot \mathrm{L}^{-1}\right)$, and phytagel $\left(7 \mathrm{~g} \cdot \mathrm{L}^{-1}\right)$ at $\mathrm{pH} 5.8$ was used to induce roots, and incubated at $25 \pm 2{ }^{\circ} \mathrm{C}$ in light for maximum 8 weeks. 
Following trifluralin treatment, the number of seeds germinated after 7 days on germination medium, the number of shoots derived per germinated seed, and the number of shoots with induced roots were recorded to analyze the effect of trifluralin on in vitro culture of cabbage.

\section{Ploidy evaluation}

The ploidy level of each successfully grown plant was analyzed by flow cytometry using leaf tissues from successfully developed plantlets. About $1 \mathrm{~cm}^{2}$ leaf tissue was chopped with a razor blade in $0.5 \mathrm{ml}$ of Otto I buffer [0.1 M citric acid monohydrate and $0.5 \%(\mathrm{v} / \mathrm{v})$ Tween 20] and the suspension was filtered through a $42 \mu \mathrm{m}$ nylon mesh. The filtrate was incubated for $10 \mathrm{~min}$ at room temperature and $1 \mathrm{ml}$ of Otto II buffer $\left(0.4 \mathrm{M} \mathrm{Na}_{2} \mathrm{HPO}_{4} \cdot 12 \mathrm{H}_{2} \mathrm{O}\right), 4 \mu \mathrm{g} \cdot \mathrm{mL}^{-1}$ 4,6-diamidino-2-phenylindole, and $2 \mu \mathrm{L} \cdot \mathrm{mL}^{-1}$ $\beta$-mercaptoethanol were added. The fluorescence intensity was measured using a CyFlow Space flow cytometer (Partec GmbH, Münster, Germany).

All the results were analyzed using factorial analysis of variance (Factorial ANOVA) with statistical software, Statistica version 13.3, and significant differences were assessed by least significant difference (LSD) at $p=0.05$. The main effect of each factor, cultivar, trifluralin concentration, and treatment condition, rate of seed germination, rate of shoot induction, and rate of root induction individually, and the interaction effect between each factor were tested.

\section{RESULTS AND DISCUSSION}

Nowadays, lack of proper knowledge of in vitro polyploidization and successful in vitro regeneration system in cabbage causes problems in the practical application of the technique in cabbage breeding. Mainly, in vitro chromosome doubling in crop plants is achieved using haploids (Dhooghe et al. 2011). As mitotic polyploidization has shown induction of important morphological and physiological changes in many crops including some Brassica species (Zhang et al. 2014, Marfil et al. 2018; Cheng et al. 2019), it is worth studying the effect and efficiency of trifluralin on in vitro cabbage culture morphogenesis and polyploidy induction. To our knowledge, this is the first report on the post effect of trifluralin on cabbage in vitro.

Among the three types of explants tested in this study, hypocotyl and calli showed a poor response for in vitro regeneration after being exposed to the trifluralin compared to the control proving the challenge of selecting appropriate explant for the successful in vitro organogenesis in conditions providing polyploid induction. In this experiment, we were not successful in shoot production from trifluralin-treated hypocotyl explant. After the trifluralin treatment, hypocotyls turned white-brown and died within one week on MS shoot induction medium. The mortality rate of the treated hypocotyls varied among cultivars as $\mathrm{Z}>\mathrm{S}>\mathrm{M}>\mathrm{F}>\mathrm{A}>\mathrm{DC}$. Zeus showed zero survival rate of the hypocotyl (data is not presented). From surviving hypocotyls following the trifluralin treatment, some cultivars showed no further growth induction from hypocotyls but remained green and alive. Cultivars that showed some shoot induction either directly from the cut ends (Fig. 1), or from calli formed at the cut ends, did not grow into elongating shoots even after several transfers into fresh media either shoot induction or shoot development media.

A similar type of response was observed from the treated calli as well. Most calli turned brown and died within one to two weeks on callus induction medium. Calli that showed growth after the treatment, either became green and dormant with zero shoot induction (Fig. 1) or shoot primordia induced from calli did not elongate. None of calli and hypocotyls of any cultivar tested resulted in successfully developed plantlets. It seemed that the tested concentrations and conditions were harsh and lethal for those fragile and sensitive explants. Cheng et al. (2012) used garlic calli to induced polyploids using trifluralin and achieved tetraploids but they also observed a reduction of survival rate of calli up to $20 \%$ when the concentration increased to $200 \mathrm{mM}$ (67.06 $\left.\times 10^{3} \mathrm{mg} \cdot \mathrm{L}^{-1}\right)$ with 15 days incubation period. Furthermore, they observed a reduction of shoot differentiation rate by $26.7 \%$ with the increase of treatment strength. 

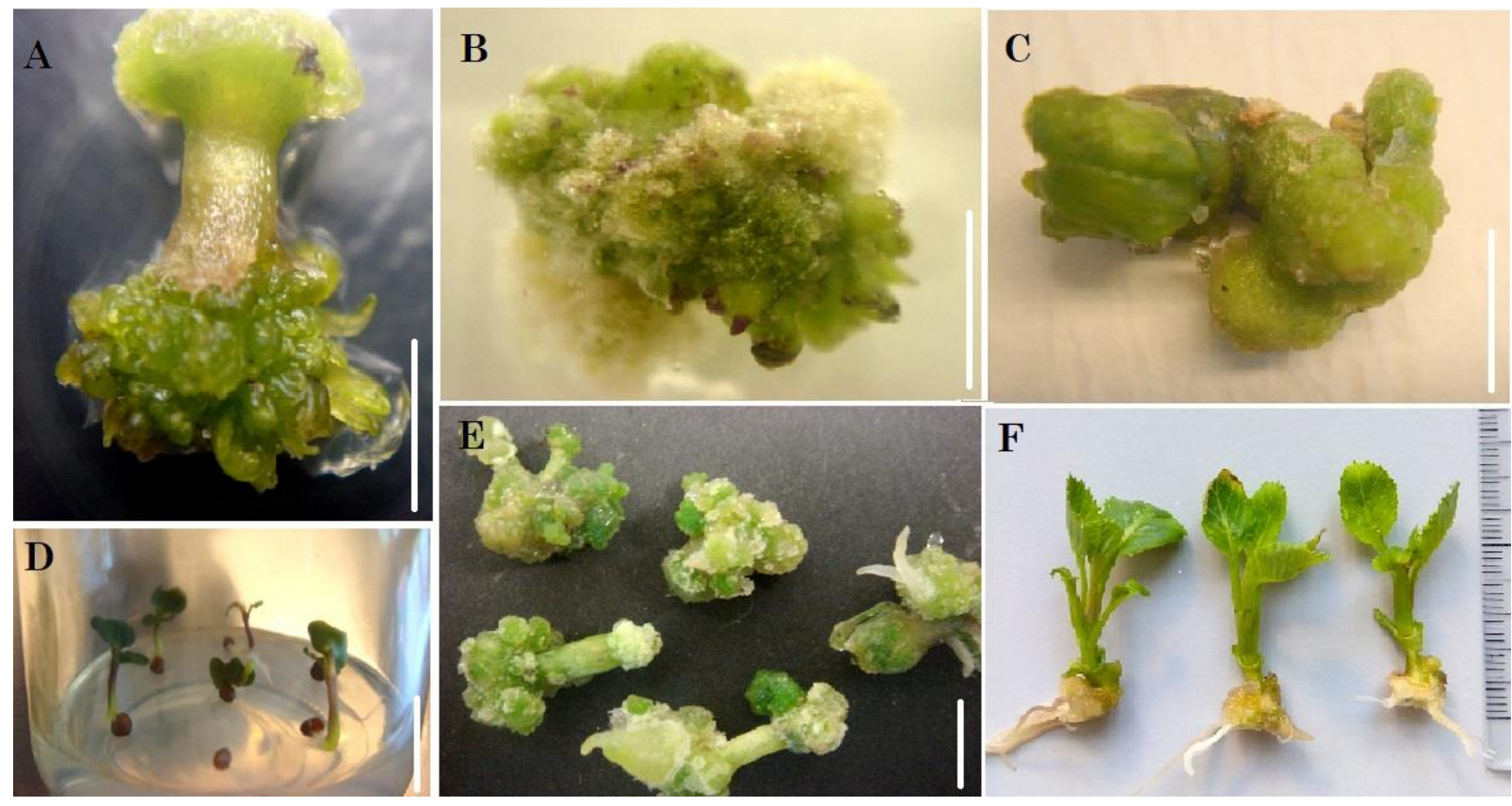

Figure 1. Organogenesis of cabbage in in vitro cultures: A - shoot induction from cut ends of treated hypocotyl on shoot induction medium in control ( $\mathrm{bar}=0.5 \mathrm{~cm}$ ); $\mathrm{B}$ - shoot induction from trifluralin treated callus on shoot induction medium (bar $=0.5 \mathrm{~cm}) ; \mathrm{C}$ - green dormant callus from treated calli on shoot induction medium $(\mathrm{bar}=0.5 \mathrm{~cm}) ; \mathrm{D}-$ germinating seeds treated with trifluralin after seven days on seed germination medium $(\mathrm{bar}=1 \mathrm{~cm}) ; \mathrm{E}-$ growing calli from treated hypocotyls after 14 days on shoot induction medium $(\mathrm{bar}=0.5 \mathrm{~cm}) ; \mathrm{F}$ - rooted shootlets derived from treated seeds

Compared to hypocotyl and calli, seeds were hopeful explants for the study. Seed germination was varied among cultivars. Compared to control, most cultivars showed a significant decrease in germination rate after the trifluralin treatments (Table 1). Germination was varied from zero to $100 \%$ depending on the treatment. For example, cultivar 'Mutsuma' did not germinate at $1.00 \mathrm{mg} \cdot \mathrm{L}^{-1}$, $24{ }^{\circ} \mathrm{C} / 24 \mathrm{~h}$, and $30^{\circ} \mathrm{C} / 24 \mathrm{~h}$, but the cultivar 'Septima' showed $100 \%$ germination at $0.5 \mathrm{mg} \cdot \mathrm{L}^{-1}$, $24^{\circ} \mathrm{C} / 24 \mathrm{~h}$, and $1.00 \mathrm{mg} \cdot \mathrm{L}^{-1}, 24^{\circ} \mathrm{C} / 48 \mathrm{~h}$. The variation in germination rate after treatments was significantly different between cultivars, treatment conditions, and concentrations tested (Fig. 2). Furthermore, a significant interaction between cultivar, treatment condition, and trifluralin concentration (Table 1) was noticed. With increased temperature, incubation period, and trifluralin concentration, the seed germination rate declined in all cultivars.

The seven-day-old seedlings were transferred into MS shoot induction medium for shoot multiplication and subcultured three times into fresh same medium within 3-4 weeks. The number of shoots obtained from one germinated seed significantly varied between cultivars (Table 1) and was not different from control. The effect of incubation temperature, duration, and trifluralin concentration on shoot multiplication was not statistically significant (Fig. 2).

The effect of trifluralin concentration, incubation temperature, and duration of root induction was significant as well as the differences between cultivars were also significant (Fig. 2). Even though the effect of treatment conditions and cultivars itself on root induction was highly significant (Table 1), no significant interactions between them (Table 1) were observed. According to Meyer et al. (2009) and Allum et al. (2007), the exposure time and concentration of the antimitotic compound and the type of explant, significantly affect survival rate and ploidy induction of Hypericum and Rosa, respectively. Too low concentration and exposure conditions could be not effective but too strong conditions might not be lethal. Understanding the interaction between concentration and exposure time is important to achieve success. In this experiment, a significant interaction between treatment conditions, concentration, and genotype on seed germination and root induction was observed. This provides a basic platform for further studies using seeds as the starting material for ploidy induction in cabbage. 
The success of ploidy induction depends on the permeability of the explant tissues and penetration of the particular antimitotic agent together with the exposure time, concentration and temperature (Allum et al. 2007). The treatment conditions and concentrations used in this study could be harsh on the viability of the majority of seeds but was not sufficient to induce polyploids from viable seeds due to poor cell permeability to have proper translocation of the chemical for its function as an antitubulin agent resulting in zero polyploids.

The ploidy level of in vitro derived plantlets from treated seeds was determined by flow cytometric analysis using young leaf tissues and none of the plants were polypoid (data is not presented). All the regenerated plants were either $2 \mathrm{x}$ or $2 \mathrm{x}+4 \mathrm{x}$. There are reports on using trifluralin as a ploidy inducing agent from different explants of different species in seedlings of Rhododendron (Eeckhaut et al. 2002), nodal segments in the family Rosaceae (Khosravi et al. 2008), nodes and shoots of Cucumis sativa (Ebrahimzadeh et al. 2018), embryos of Spathiphyllum wallsii (Eeckhaut et al. 2004), or in microspores of cabbage (Rudolf et al. 1999; Yuan et al. 2015; Li et al. 2020). There are no reports on using cabbage seeds as explants in vitro conditions.
Kumar and Dwivedi (2014) used inbred seeds of cultivar B. campestris IC363713 to induce polyploids ex vitro employing colchicine, but they were unable to achieve any polyploids. Niimi et al. (2015) treated seeds and in vitro germinated seedlings of B. oleracea var. acephala (kale) with colchicine or amiprophos-methyl. They achieved the high frequency of tetraploids $(24 \%)$ from APM $\left(9 \mathrm{mg} \cdot \mathrm{L}^{-1}\right.$ for 24 hours) treated seeds. In our study as well, we thought the seeds were a hopeful starting material for in vitro culture development in trifluralin mediated cabbage polyploid induction studies.

We observed a significant reduction of seed germination with the increase of trifluralin concentration and incubation temperature and duration. The shoot multiplication increased with increased incubation temperature and duration though it reduced with increased concentration. Thus, in the future, we plan to conduct experiments on the effect of increased temperature, incubation period, and a lower concentration of trifluralin aiming to increase the efficiency of polyploid induction. Furthermore, it is possible that the use of pre-induced germinating seeds to increase chemical penetration would be successful in achieving induction of polyploids in cabbage.

Table 1. Results of ANOVA to test the influence of cultivar, trifluralin concentration, treatment condition on in vitro culture of cabbage starting from seeds

\begin{tabular}{|c|c|c|c|c|}
\hline Trait & Effect & MS & $\mathrm{F}$ & $\mathrm{P}$ \\
\hline \multirow{7}{*}{ Rate of seed germination } & cultivar & 11339.3 & 87.4 & $0.0000 *$ \\
\hline & trifluralin concentration & 33654.1 & 259.3 & $0.0000 *$ \\
\hline & treatment condition & 7613.4 & 58.668 & $0.0000 *$ \\
\hline & treatment condition $\times$ cultivar & 638.6 & 4.9213 & $0.0000 *$ \\
\hline & treatment condition $\times$ concentration & 382.4 & 2.9465 & $0.0015^{*}$ \\
\hline & concentration $\times$ cultivar & 925.4 & 7.131 & $0.000 *$ \\
\hline & treatment $\times$ concentration $\times$ cultivar & 237.4 & 1.829 & $0.00262 *$ \\
\hline \multirow{7}{*}{ Shoots per germinated seed } & cultivar & 17.91 & 2.813 & $0.014 *$ \\
\hline & trifluralin concentration & 4.4 & 0.692 & 0.5990 \\
\hline & treatment condition & 6.5 & 1.021 & 0.3867 \\
\hline & treatment condition $\times$ cultivar & 10.05 & 1.5795 & 0.0799 \\
\hline & treatment condition $\times$ concentration & 9.34 & 1.4674 & 0.1492 \\
\hline & concentration $\times$ cultivar & 9.53 & 1.4972 & 0.0860 \\
\hline & treatment $\times$ concentration $\times$ cultivar & 6.96 & 1.094 & 0.337 \\
\hline \multirow{7}{*}{ Rate of root induction } & cultivar & 10575.3 & 47.1 & $0.0000 *$ \\
\hline & trifluralin concentration & 23284.8 & 103.6 & $0.0000 *$ \\
\hline & treatment condition & 6557.2 & 29.186 & $0.0000 *$ \\
\hline & treatment condition $\times$ cultivar & 377.3 & 1.6793 & 0.05559 \\
\hline & treatment condition $\times$ concentration & 717.0 & 3.1912 & $0.00068 *$ \\
\hline & concentration $\times$ cultivar & 1636.5 & 7.2842 & $0.0000^{*}$ \\
\hline & treatment $\times$ concentration $\times$ cultivar & 446.7 & 1.988 & $0.000749 *$ \\
\hline
\end{tabular}



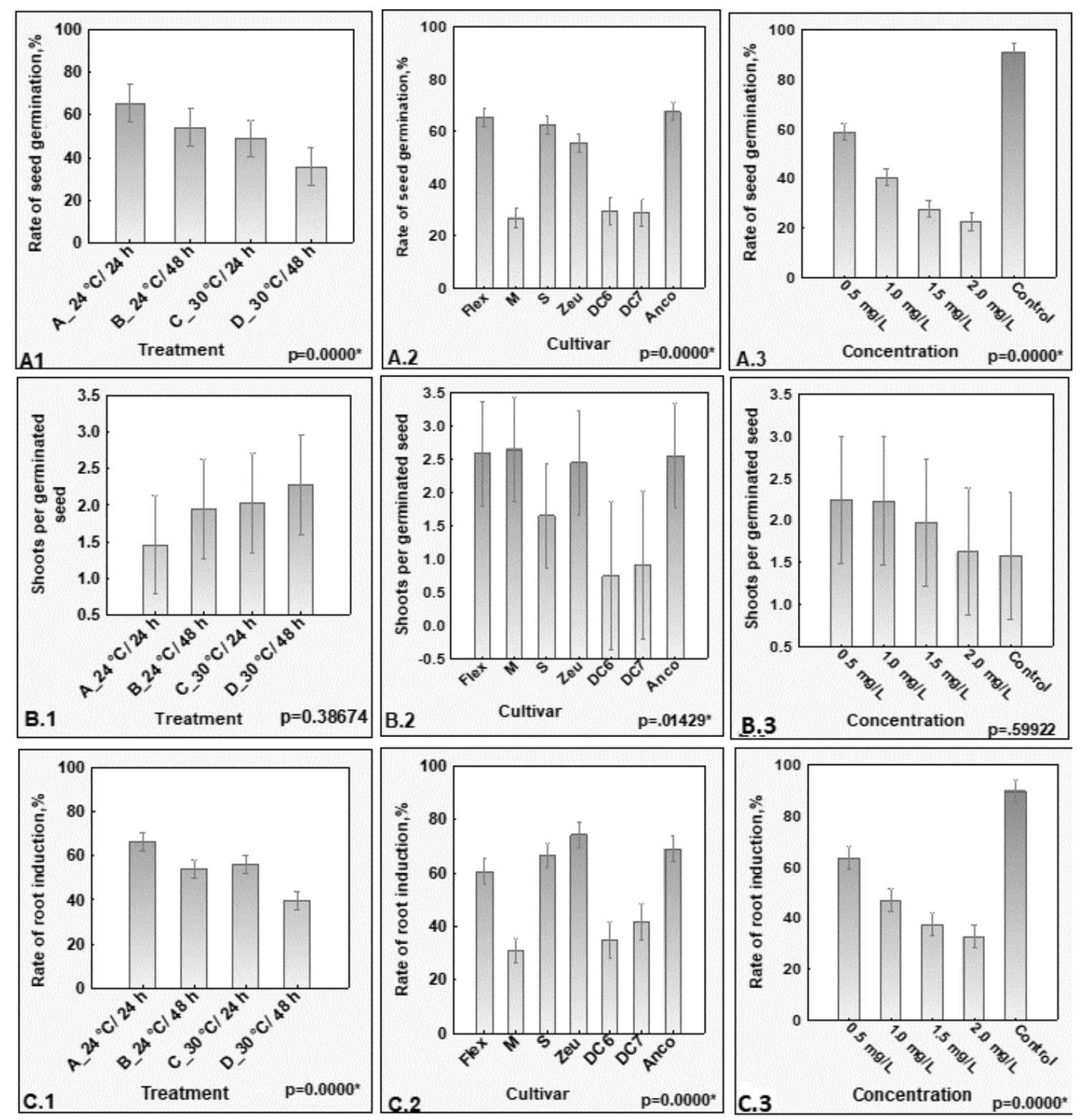

Figure 2. Effect of cultivar, trifluralin concentration, treatment condition on in vitro culture of seeds and their interaction with each other: A1, B1, C1 - the effect of different treatment conditions on the rate of seed germination, shoot induction, and root induction respectively; A2, B2, C2 - the effect of different cultivars on the rate of seed germination, shoot induction, and root induction respectively; A3, B3, C3 - the effect of different concentrations of trifluralin on seed germination, shoot induction, and root induction respectively. Vertical bars denote 0.95 confidence intervals

\section{CONCLUSION}

From three different types of explants tested, seeds can be most prospective as the potential explants for further studies on establishing of in vitro protocol usable for producing cabbage polyploids using trifluralin. To maximize the success of in vitro culture, namely organogenesis together with efficient ploidy induction, the careful optimization of treatment conditions and culture protocol for individual cabbage cultivar and a better understanding of the performance of each cultivar is required.

\section{Acknowledgments}

This project was financially supported by the Grant, NAZV: QK1910235 provided by the Ministry of Agriculture of the Czech Republic and the Internal Grant Agency of the Faculty of Tropical AgriSciences, Czech University of Life Sciences Prague, IGA (Project No. 20205006). 


\section{Author Contributions}

O.A.J.A. designed and performed experimental work, data analyzes, interpretations, and writing the manuscript. I.V. participated in interpretations, revision, and guiding manuscript writing, M.K. supported in designing the experiment and provided supervision on the work and guiding manuscript writing. All the authors read and approved the final manuscript.

\section{Conflicts of Interest}

The authors declare no conflict of interest.

\section{REFERENCES}

Allum J.F., Bringloe D.H., Roberts A.V. 2007. Chromosome doubling in a Rosa rugosa Thunb. hybrid by exposure of in vitro nodes to oryzalin: the effects of node length, oryzalin concentration and exposure time. Plant Cell Reports 26: 1977-1984. DOI: 10.1007/s00299-007-0411-y.

Cheng Z.-H., Zhou X.-J., Khan M.A., Su L., Meng H.-W. 2012. In vitro induction of tetraploid garlic with trifluralin. Genetics and Molecular Research 11(3): 2620-2628. DOI: 10.4238/2012.july.10.13.

Cheng W., Tang M., Xie Y., Xu L., Wang Y., Luo X. et al. 2019. Transcriptome-based gene expression profiling of diploid radish (Raphanus sativus L.) and the corresponding autotetraploid. Molecular Biology Reports. 46: 933-945. DOI: 10.1007/s11033-0184549-1.

Dhooghe E., Van Laere K., Eeckhaut T., Leus L., Van Huylenbroeck J. 2011. Mitotic chromosome doubling of plant tissues in vitro. Plant Cell, Tissue and Organ Culture 104: 359-373. DOI: 10.1007/s11240-010-9786-5.

Ebrahimzadeh H., Soltanloo H., Shariatpanahi M.E., Eskandari A., Ramezanpour S.S. 2018. Improved chromosome doubling of parthenogenetic haploid plants of cucumber (Cucumis sativus L.) using colchicine, trifluralin, and oryzalin. Plant Cell, Tissue and Organ Culture 135: 407-417. DOI: 10.1007/s11240-018-1473-y.

Eeckhaut T., Samyn G., Van Bockstaele E. 2002. In vitro polyploidy induction in Rhododendron simsii hybrids. Acta Horticulturae 572: 43-49. DOI: 10.17660/actahortic.2002.572.4.
Eeckhaut T.G.R., Werbrouck S.P.O., Leus L.W.H., Van Bockstaele E.J., Debergh P.C. 2004. Chemically induced polyploidization in Spathiphyllum wallisii Regel through somatic embryogenesis. Plant Cell, Tissue and Organ Culture 78: 241-246. DOI: 10.1023/b:ticu.0000025659.19232.04.

Hansen N.J.P., Andersen S.B. 1996. In vitro chromosome doubling potential of colchicine, oryzalin, trifluralin, and APM in Brassica napus microspore culture. Euphytica 88: 159-164. DOI: 10.1007/bf00032447.

Hansen N.J.P., Andersen S.B. 1998. Efficient production of doubled haploid wheat plants by in vitro treatment of microspores with trifluralin or APM. Plant Breeding 117: 401-405. DOI: 10.1111/j.14390523.1998.tb01963.x.

Khosravi P., Kermani M.J., Nematzadeh G.A., Bihamta M.R., Yokoya K. 2008. Role of mitotic inhibitors and genotype on chromosome doubling of Rosa. Euphytica 160: 267-275. DOI: 10.1007/s10681007-9571-7.

Kumar G., Dwivedi K. 2014. Induced polyploidization in Brassica campestris L. (Brassicaceae). Cytology and Genetics 48: 103-110. DOI: 10.3103/s0095452714020066

Li Q., Shi Y., Wang Y., Liu L., Zhang X., Chen X. et al. 2020. Breeding of cabbage lines resistant to both head splitting and fusarium wilt via an isolated microspore culture system and markerassisted selection. Euphytica 216; 34; 9 p. DOI: $10.1007 / \mathrm{s} 10681-020-2570-7$

Marfil C.F., Duarte P.F., Masuelli R.W. 2018. Phenotypic and epigenetic variation induced in newly synthesized allopolyploids and autopolyploids of potato. Scientia Horticulturae 234: 101-109. DOI: 10.1016/j.scienta.2018.02.022.

Meyer E.M., Touchell D.H., Ranney T.G. 2009. In vitro shoot regeneration and polyploid induction from leaves of Hypericum species. HortScience 44(7): 1957-1961. DOI: 10.21273/hortsci.44.7.1957.

Murashige T., Skoog F. 1962. A revised medium for rapid growth and bio assays with tobacco tissue cultures. Physiologia Plantarum 15: 473-497. DOI: 10.1111/j.1399-3054.1962.tb08052.x. 
Niimi H., Watanabe M., Serizawa Y., Koba T., Nakamura I., Mii M. 2015. Efficient in vitro production of nonchimeric tetraploid in kale (Brassica oleracea L. var acephala) and its evaluation as a functional crop. Global Advanced Research Journal of Agricultural Science 4(7): 280-301.

Orcen N., Emiroglu U. 2014. Antimitotic effects of acenaphthene and trifluralin on androgenic tobacco haploids. Fresenius Environmental Bulletin 23(2): 382-384.

Petersen K.K., Hagberg P., Kristiansen K. 2003. Colchicine and oryzalin mediated chromosome doubling in different genotypes of Miscanthus sinensis. Plant Cell, Tissue and Organ Culture 73: 137-146. DOI: 10.1023/a:1022854303371.

Rudolf K., Bohanec B., Hansen M. 1999. Microspore culture of white cabbage, Brassica oleracea var. capitata L.: Genetic improvement of non-responsive cultivars and effect of genome doubling agents.
Plant Breeding 118: 237-241. DOI: 10.1046/j.1439-0523.1999.118003237.x.

Sattler M.C., Carvalho C.R., Clarindo W.R. 2016. The polyploidy and its key role in plant breeding. Planta 243: 281-296. DOI: 10.1007/s00425-015-2450-X. Yuan S., Su Y., Liu Y., Li Z., Fang Z., Yang L. et al. 2015. Chromosome doubling of microspore-derived plants from cabbage (Brassica oleraceae var. capitata L.) and broccoli (Brassica oleraceae var. italica L.). Frontiers in Plant Science 6; 1118; 10 p. DOI: 10.3389/fpls.2015.01118.

Zhang Y., Zhang S., Ren J., Hou X., Xiong A., Li Y. et al. 2014. Induction of tetraploidy in non-heading Chinese cabbage (Brassica campestris ssp. chinensis Makino) by colchicine treatment increases the ascorbic acid concentration. Journal of Horticultural Science and Biotechnology 89(1): 53-60. DOI: 10.1080/14620316.2014.11513048. 